SOI: $1.1 /$ TAS $\quad$ DOI: $10.15863 /$ TAS

International Scientific Journal Theoretical \& Applied Science

p-ISSN: 2308-4944 (print) e-ISSN: 2409-0085 (online)

Year: $2018 \quad$ Issue: $01 \quad$ Volume: 57

Published: $30.01 .2018 \quad$ http://T-Science.org

SECTION 31. Economic research, finance, innovation, risk management.
Dmitry Olegovich Bordukh bachelor, Institute of Entrepreneurship and Sevice sector (branch) DSTU, g. Shakhty

Yury Dmitrievich Mishin Professor, candidate of philosophical Sciences, Department of "Philosophy and Culturology" of Siberian state transport University, Novosibirsk

Maria Valeryevna Reva the Department of "Private animal husbandry and feeding of farm animals" "Don state agrarian University" in the village of Persianovka, Rostov region

Vladimir Timofeevich Prokhorov Department of "Design,technology, and design" Institute of service sector and entrepreneurship in Shakhty, Rostov region

Stanislav Matveyevich Zverev JSC "Roslegprom" in city Moscow

\title{
ON THE ALLIANCE OF CULTURE AND PARTICIPATIVE MANAGEMENT TO ENSURE THE PRODUCTION OF DEMANDED AND COMPETITIVE PRODUCTS BY CONSUMERS IN THE REGIONS OF THE SOUTHERN FEDERAL DISTRICT AND THE NORTH CAUCASUS FEDERAL DISTRICT
}

\begin{abstract}
In the article the authors consider the possibilities of the union of culture and participative management to ensure the production of demanded and competitive products by consumers in the regions of the Southern Federal District and the North Caucasus Federal District. Besides, the authors consider that control within the framework of the QMS carries a psychological load and form a sense of responsibility for the implementation of the formulated tasks. But this is subject to the fact that competent selection and recruitment of personnel will be realized, in which there is communication, professionalism and stress resistance.

Key words: quality, demand, competitiveness, production, quantity, measure, market, system, consumer, producer, consumer culture, quality activity, quality of life, purchasing qualification, economic policy.

Language: Russian

Citation: Bordukh DO, Mishin YD, Reva MV, Prokhorov VT, Zverev SM (2018) ON THE ALLIANCE OF CULTURE AND PARTICIPATIVE MANAGEMENT TO ENSURE THE PRODUCTION OF DEMANDED AND COMPETITIVE PRODUCTS BY CONSUMERS IN THE REGIONS OF THE SOUTHERN FEDERAL DISTRICT AND THE NORTH CAUCASUS FEDERAL DISTRICT. ISJ Theoretical \& Applied Science, 01 (57): 337-357.

Soi: http://s-o-i.org/1.1/TAS-01-57-46 Doi: crossef https://dx.doi.org/10.15863/TAS.2018.01.57.46

\section{UDC685.34: 519.74}

\section{О СОЮЗЕ КУЛЬТУРЫ И ПАРТИСИПАТИВНОГО УПРАВЛЕНИЯ ДЛЯ ОБЕСПЕЧЕНИЯ ПРОИЗВОДСТВА ВОСТРЕБОВАННОЙ И КОНКУРЕНТОСПОСОБНОЙ ПРОДУКЦИИ ПОТРЕБИТЕЛЯМИ РЕГИОНОВ ЮФО И СКФО}

Аннотация: в статье авторы рассматривают возможности союза культуры и партисипативного управления для обеспечения производства востребованной и конкурентоспособной продукции потребителями регионов ЮФО и СКФО. Кроме того, авторы считают, что контроль в рамках СМК несет психологическую нагрузку и формируют у коллектива чувство ответственности за реализацию сформулированных задач. Но это при условии, что будет реализован грамотный отбор и набор персонала, у которого в наличии коммуникабельность, профессионализм и стрессоустойчивость.
\end{abstract}


Ключевые слова: качество, востребованность, конкурентоспособность, продукиия, количество, мера, рынок, системность, потребитель, производитель, потребительская культура, качественная деятельность, качество жизни, покупательская квалификация, экономическая политика.

\section{Введение}

Необходимость совершенствования системы менеджмента качества на предприятиях легкой промышленности обусловлено следующими важными причинами. Во-первых, это повышение доверия потенциальных потребителей к продукции, которую выпускает данное предприятие. Во-вторых, это возможность значительно укрепить свое положение на уже существующих рынках, а также значительно расширить сферы влияния путем выхода на новые отечественные и зарубежные рынки. И втретьих - это значительное повышение производительности труда любого промышленного предприятия на котором предполагается внедрение СМК с использованием партисипативного управления.

\section{Основная часть}

В настоящее время на предприятиях большое значение уделяют мотивации сотрудников, так как в зависимости от того, насколько сотрудник мотивирован, будут видны и результаты его деятельности. Основной задачей менеджеров становится полное задействование в работе всего потенциала сотрудников. Причем менеджеры понимают, что материальное стимулирование не повышает лояльность и приверженность предприятия. Партисипативное управление решает эту проблему.

Суть такого управления состоит в том, что при нем сотрудники предприятия включаются в процесс управления, участвуют в деятельности предприятия, принимают решения по ряду вопросов. Причем, если сотрудник предприятия имеет право голоса, принимает участие в деятельности предприятия, получая за это вознаграждение, тогда он будет работать более качественно и производительно. Сотрудник, с мнением которого считаются, идеи которого внедряются, будет лучше относиться к месту своей работы и будет работать с полной отдачей.

При партисипативном управлении сотрудники могут обговаривать с руководителем цели и задачи, которые ему будет необходимо выполнить. Сотрудники предприятия могут сформировать рабочие группы из тех сотрудников, с которыми им было бы приятно и комфортно работать. Помимо этого сотрудники предприятия могут выдвигать свои идеи и предложения по поводу усовершенствования работы предприятия в целом. Причем, за выдвижение идей должно идти и вознаграждение.

Партисипативное управление имеет ряд преимуществ. Участие в управлении сотрудников приводит к повышению качества принимаемых решений, поскольку работники могут обладать той информацией, которая не известна руководителю. При таком управлении сотрудники могут проявить в полной мере себя, показать свои знания и умения, а также почувствовать свою значимость для предприятия, таким образом повышая свою мотивацию. В основе мотивации обычно присутствуют не только личные достижения сотрудника, но и общий результат работы предприятия . Объединение сотрудников по рабочим группам наилучшим образом может отразиться на корпоративном духе предприятия

Тем не менее, партисипативный подход помимо преимуществ имеет и свои недостатки. Не все люди в силу своего характера готовы участвовать в управлении организацией и выдвигать идеи и предложения, неся за них ответственность. Многим сотрудникам гораздо проще выполнять работу по указанию руководителя. Привлечение работников к управлению на предприятии может не лучшим образом отразиться на менеджерах, так как они могут потерять свое влияние на сотрудников. Много времени также будет уходить на обсуждение проблем, при этом однозначного решения может быть и не принято, а времени потрачено. Многие идеи и предложения сотрудников предприятия могут быть нерациональными и неуместными в силу недостаточности знаний. Поэтому, руководителям предприятия необходимо информировать сотрудников о положении дел на предприятии, обучать персонал с целью углубления знаний и выдвижения более эффективных и актуальных предложений. Отсутствие признания идеи работника может вызвать неоднозначную реакцию у сотрудника, выдвигающего свои инновационные предложения, тем самым демотивируя его. Поэтому руководителям предприятия необходимо объяснять, почему данная идея не подходит в той или иной ситуации.

Рассмотрев все плюсы и минусы партисипативного управления, можно сделать вывод, что такое управление не является спасательным средством для улучшения дел на предприятии, но оно позволяет увидеть проблемы организации изнутри и попытаться решить их не усилиями одного человека, а всем коллективом , где каждый сможет проявить себя 
на благо предприятия .

Независимо от того, что партисипативный метод управления кадрами предприятия получает с каждым годом все большее одобрение в большинстве стран с развитой и развивающейся экономикой, российские предприятия легкой промышленности пока не готовы внедрить и полностью осознать преимущества этого метода. Всё это потому, что службы управления кадрами предпочитают работать по сложившейся традиционной схеме.

Большая часть российских предприятий, как долго действующих, так и недавно созданных, использует директивный метод управления. На таких предприятиях управленческие решения принимаются единолично, рост по карьерной лестнице идет за счет «хороших связей» с руководителем, а не собственных заслуг в работе, частые нарушения трудового законодательства являются обычным делом. Причиной, по которой отдается предпочтение директивному методу, является сложившийся на протяжении многих веков национальный менталитет нашей страны, а также присутствующая до сих пор советская идеология на многих предприятиях. Вследствие этого, менеджмент на таких предприятиях централизован, административен и носит характер формальности.

$\mathrm{He}$ более половины менеджеров по управлению персоналом могут достичь и умело использовать согласованность поставленных целей с возможностями предприятия и интересами сотрудников.

Еще одним очень важным фактором, не позволяющим принять парситипативный метод управления персонала на российские предприятия, можно принять влияние национальной культуры России. От этого влияния зависит выбор стратегии управлением кадровыми ресурсами в практической деятельности предприятия.

К культурной особенности российских предпринимателей, по мнению большинства исследователей, использовавших системный подход, при определении относится зависимость от коллектива и сформированных им нормам поведения, стремление к доверительным отношениям, уход от ответственности. Часто отдается предпочтение личным качествам сотрудника, чем его успех в выполненной работе, происходит смешивание личных и деловых отношений. Также нашей российской действительностью замечена склонность предпринимателей и их сотрудников к подкупу, скрытие доходов от налоговой службы, подделка документов, пренебрежение к этическим нормам по отношению к конкурентам. Между руководителем и сотрудником проявляется разрыв в общении, по-другому можно сказать, что руководитель предприятия недоступен для работников низшего звена. Замечено также, что россияне имеют средний уровень индивидуальности и часто стараются отойти от неопределенности.

Вследствие всего вышесказанного, напрашивается вывод о том, что в России предприятия и руководство управления персоналом сформированы неэффективно и рабочие коллективные связи практически отсутствуют. Предприятия уделяют всё своё внимание на выполнение условий, которые поставил перед ними государственный бюрократический аппарат, а не на выполнение ответственности перед потребителями и обществом. Поэтому, возникает трудность внедрения «западных» методов управления в российскую практику.

Для того, чтобы наиболее успешно внедрить парситипативное управление кадрами и подготовить сотрудников к изменению подхода работы в коллективе, прежде всего необходимо установить меры по поощрению индивидуальности в каждом работнике предприятия и устранить устоявшуюся недоступность руководителя для низшего звена. Важно создать качественную и действующую систему мотивации и постоянное повышение квалификации, чтобы персонал стал источником конкурентоспособности предприятия, соответствовал современным требованиям к управлению человеческими ресурсами.

Руководство по качеству направлено на применение «процессного подхода» при разработке, внедрении и улучшении результативности системы менеджмента качества c целью повышения удовлетворенности потребителей путем выполнения их требований.

Преимущество процессного подхода состоит в непрерывности управления, которое он обеспечивает на стыке отдельных процессов в рамках системы, а также при их комбинации и взаимодействии.

Основными процессами системы менеджмента качества являются: проектирование и разработка продукции;

составление плана производства; производство; контроль и проведение испытаний продукции;

упаковка и хранение продукции; продажа; закупки; обеспечение ресурсами; проведение маркетинговых исследований. Виды деятельности по измерению и 
мониторингу для обеспечения и верификации соответствия продукции определены в комплексной документации, производственных планах и сменных заданиях, технологических процессах, процедурах по измерению, анализу и улучшению.

Деятельность по мониторингу, измерениям, анализу и улучшению включает в себя: исследование удовлетворенности потребителей;

внутренний аудит;

мониторинг и измерение процессов; мониторинг и измерение продукции; управление несоответствующей

продукцией;

непрерывное улучшение, в том числе корректирующие и предупреждающие действия; определение мест применения инженерных и статистических методов.

Проявившиеся в сфере реализации изготовленной продукции дефекты свидетельствуют не только о плохом качестве продукции, но больше о неудовлетворительной работе предприятия

Снижение таких случаев будет возможным за счёт использования партисипативного управления реализацией Политики и целей в области качества и процедур, разработанных руководством предприятия в рамках системы менеджмента качества, формирующие требования ко всем участникам процесса по созданию условий на предприятии для производства бездефектной продукции и при жестком контроле за их выполнением, а именно:

1.Руководство по качеству. Является основополагающим документом системы менеджмента. Руководство по качеству описывает структуру и содержание системы менеджмента качества, направленную на обеспечение соответствия продукции требованиям потребителя и обязательным требованиям нормативной документации (НД), а также излагает Процедуры (или дает ссылки на них), разработанные в рамках СМК, описывает взаимодействие между процессами системы менеджмента качества.

2.Внутренний аудит системы менеджмента качества. Настоящая процедура является обязательной документированной процедурой, которая устанавливает порядок и последовательность действий при проведении внутренних аудитов (проверок) системы менеджмента качества.

$$
\text { 3. «Гарантийный ремонт }
$$
продукции»Настоящий документ описывает процесс «Гарантийный ремонт продукции» и устанавливает порядок работы с претензиями потребителей.
4.Управление документацией и записями. Управляемыми считаются документы, подготовка, идентификация, рассмотрение, согласование, распределение, хранение и пересмотр которых осуществляется на основе заранее установленных, систематически используемых правил.

5.Управление несоответствующей продукцией.Настоящий документ является обязательной документированной процедурой, которая устанавливает: а) конкретные обязанности структурных подразделений, должностных лиц и отдельных исполнителей по управлению несоответствующей продукцией; б) цели, задачи, сроки, порядок оформления и регистрации записей и документов по управлению несоответствующей продукцией в основном и вспомогательном производстве.

6.Организация контроля качества. Настоящий документ устанавливает: а) порядок организации контроля качества продукции на предприятии; б) конкретные обязанности должностных лиц и отдельных исполнителей по контролю качества продукции предприятия, управлению и идентификации несоответствующей продукции.

7.Закупки. Настоящая процедура устанавливает порядок работы в области оценки и выбора поставщиков, ведения анкеты по поставщикам и определения категории надежности поставщика, определяет единый порядок проведения закупок комплектующих изделий, материалов и полуфабрикатов, их складирования, обеспечения производства и эффективную работу с потребителями продукции.

8.Проектирование, разработка ассортимента и его производство. Настоящий документ устанавливает порядок выполнения процесса «Проектирование, разработка ассортимента и его производство » и предназначен для: а) регламентации и управления деятельностью подразделения по проектированию и разработке новых видов продукции; б) постоянного улучшения системы менеджмента качества и результатов процесса изготовления востребованной продукции.

9.Производство продукции. Настоящий документ устанавливает порядок выполнения процесса «Производство продукции» и предназначен для регламентации и управления деятельностью подразделений по производству продукции».

10.Удовлетворенность потребителей. Для определения динамики удовлетворенности потребителя менеджер СМК собирает и систематизирует данные из информационных источников. Источниками информации об удовлетворенности потребителей являются: 
анкета оценки удовлетворенности потребителя; отзывы потребителей; объемы выпускаемой продукции; объемы реализованной продукции; премии, награды и дипломы.

11.Технологическая подготовка производства. Настоящий документ устанавливает порядок выполнения процесса «Технологическая подготовка производства» и предназначен для: а) для регламентации и управления деятельностью подразделения по технологической подготовке производства новых видов продукции. б) постоянного улучшения системы менеджмента качества и результатов процесса.

12. Организация и порядок проведения «Дней качества». «День качества» - это оперативное совещание руководителей структурных подразделений, посвященное контролю и анализу качества работы предприятия и его подразделений.

13.Статистические методы управления качеством. Статистический контроль качества продукции является элементом механизма управления качеством продукции и регулирования взаимоотношений между поставщиком и потребителем, при этом проверка изготовленного ассортимента изделий осуществляется до и после его изготовления, а не только по ходу его изготовления.

Главная цель применения статистических методов - регулирование процесса создания изделия высокого качества на всех стадиях от маркетинга до эксплуатации с меньшими экономическими затратами и высокой эффективностью.

Статистические методы предусматривают сбор, систематизацию и математическую обработку результатов производственной деятельности, анализ информации для принятия корректирующих и предупреждающих мер, дальнейшее исследование объекта контроля для достижения приемлемого (оптимального) уровня качества.

Внедрение системы качества представляет собой комплекс работ, который затрагивает различные аспекты деятельности предприятия и его подсистемы - подсистему стратегического управления, производственную подсистему, подсистему логистики, управление персоналом, внутренние коммуникации, документооборот и др. В связи с этим, внедрение системы качества является достаточно трудной, длительной и трудоемкой задачей. Решение этой задачи, как правило, происходит в несколько этапов.

Сформулируем основные этапы внедрения СМК, а именно: совершенствование СМК имеет смысл только в том случае, если у коллектива предприятия есть желание добиться весомых результатов в борьбе за качество своей продукции, но все это должно провоцировать желание коллективов достичь новых высот, двигаться вперед и гарантировать себе и своим предприятиям стабильные результаты от своей деятельности.

Для реализации сформулированных процедур, пожеланий должны быть выполнены следующие мероприятия, а именно:

* маг 1 - осознание высшим руководством цели создания и внедрения СМК на предприятии;

*маг 2 - установление потребностей $и$ ожиданий потребителей $u$ других заинтересованных сторон;

*шаг 3 - формирование стратегии управления, Политики и Целей в области качества;

* шаг 4 - организаџия обучения в области качества всех сотрудников;

* шаг 5 - планирование работ по внедрению $C M K$;

* шаг 6 - внедрение СМК с формированием команды, состоящей из различных специилистов;

* шаг 7 - установление системы процессов, их согласованной взаимосвязи и взаимодействия, выделение ключевых проиессов, необходимых для достижения иелей в области качества;

* шаг 8- документирование СМК (в том объеме и степени конкретизации, необходимом именно для вашего предприятия - не забывая об обязательности некоторой документации в соответствии с требованиями ИСО 9001-2015);

* шаг 9 - внутренние аудиты,

* щаг 10 - доработка документаџии СМК и устранение замечаний по результатам внутренних аудитов и отработки при внедрении в действие разработанной нормативной документации;

* uar 11 - сертификация СМК;

* шаг 12 - дальнейтее развитие СМК.

Предприятие легкой промышленности регионов ЮФО и СКФО определили и осуществляют менеджмент многочисленных взаимосвязанных видов деятельности. Процедуры были идентифицированы, описаны и задокументированы.

Кроме того, разработали, задокументировали, внедрили и поддерживаем в рабочем состоянии систему менеджмента качества, что обеспечило предприятию постоянное улучшение его результативности в соответствии с требованиями ГОСТ Р ИСО 9001: 2015.

Такими процедурами в рамках системы менеджмента качества являются:

Основные процедуры:

^ проектирование, разработка, изготовление опытных образцов и постановка на серийное производство ЛП 08 -01;

^ составление плана производства ЛП 03-01; 
^контроль и проведение испытаний продукции на её соответствие требованиям технических регламентов;

^ упаковка и хранение (производится согласно типовых и индивидуальных технологических процессов на каждое изделие);

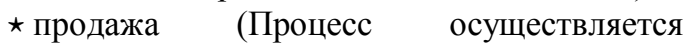
торговыми организациями, или маркетинговыми службами предприятия);

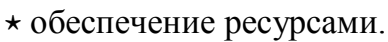

Процедуры менеджмента:

^ процессы управленческой деятельности руководства;

^ проведение маркетинговых исследований;

夫 определены последовательности и взаимодействия процессов;

夫 определены для каждой процедуры критериев и методов, необходимые для обеспечения результативности, как при осуществлении, так и при управлении этими процедурами.

Порядок выбора критериев изложен в ЛП 0101 «Порядок разработки, оформления, согласования и утверждения процессов системы менеджмента качества» и предполагает:

*обеспечивать для каждого процесса наличие ресурсов и информации, необходимых для поддержки этих процессов и их мониторинга;

* осуществлять мониторинг, измерение и анализ этих процессов;

* принимать меры, необходимые для достижения запланированных результатов и постоянного улучшения этих процессов;

*осуществляются процессы обеспечения управлением: в части маркетинга-это совместное участие в выставках, выдача задания на проведение рекламы и исследования тенденций рынка, в части продажи- это договор на реализацию продукции.

Переданные \результаты разработки, документирования и внедрения системы менеджмента качества подтверждаются внутренним аудитом (ЛП 13-03), проводимым по программе аудита ежеквартально.

Внутренние аудиты СМК на предприятии проводятся с целью:

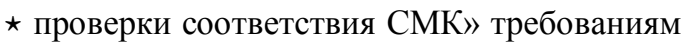
ISO 9001:2015 (ГОСТ Р ИСО 9001-2015);

夫оценки соответствия СМК требованиям, установленным внутренней документацией предприятий легкой промышленности ;

夫оценки способности СМК к результативному и эффективному функционированию;

^проверки выполнения и результативности корректирующих и предупреждающих действий по несоответствиям, выявленным при проведении предыдущих аудитов;

* определения областей деятельности для улучшения, возможности и путей совершенствования СМК.

Внутренние аудиты (проверки) проводятся: плановый аудит ежеквартально согласно программе проведения внутреннего аудита СМК, утвержденной вместе с приказом о проведении внутренних аудитов руководителями предприятий легкой промышленности, a внеплановый аудит - основанием для него служит:

* увеличение количества замечаний или рекламаций на выпускаемую продукцию;

* ухудшение качества выпускаемой продукции;

* проверка реализации корректирующих и предупреждающих действий и оценки их эффективности;

* изменения структуры управления предприятием;

* необходимость совершенствования процедур, процессов СМК предприятия;

* иные причины.

Аудиты может проводить как менеджер по СМК, так и другие работники предприятия.

Подбор группы по аудиту осуществляет заместитель исполнительного директора по качеству с учетом необходимости обеспечения независимости аудиторов от проверяемой деятельности; или иных факторов, способных оказать влияние на результативность и эффективность внутреннего аудита СМК.

Главный аудитор с группой по аудиту в ходе проведения внутреннего аудита СМК осуществляют сбор информации с целью проверки соответствия СМК требованиям международного стандарта ГОСТ Р ИСО 9001:2015, выполнения требований потребителя и требований документов СМК, результативности и эффективности внедрения записей и поддержания их в рабочем состоянии, знания и понимания Политики и Целей предприятий в области качества, степень достижения целей в области качества, определения возможности улучшения СМК.

Методы сбора информации включают:

^ опрос должностных лиц;

* наблюдение за деятельностью, производственной средой;

^ анализ документации.

Информация, выявленная в процессе внутреннего аудита СМК, фиксируется аудиторами.

По окончании аудита главный аудитор составляет отчет по внутреннему аудиту СМК. Отчет должен содержать полную, точную и однозначно понимаемую информацию по проведенному аудиту. Этот отчет является одним из видов записей по качеству и необходим для оценки СМК и принятия решений об ее 
улучшении. Копии отчета направляются руководителям структурных подразделений и высшему руководству.

Предприятия легкой промышленности планируют и проводят проверки системы менеджмента качества в соответствии с ЛП 13-03 «Внутренний аудит системы менеджмента качества»

$\begin{array}{ccr}\text { Высшее } & \text { руководство } & \text { предприятия } \\ \text { ежеквартально } & \text { анализирует } & \text { систему }\end{array}$
менеджмента качества с целью обеспечения ее постоянной пригодности, адекватности и результативности. В анализ включается оценка возможностей улучшения и потребности в изменениях в системе менеджмента качества предприятия, в том числе в Политике и целях в области качества. Руководство по качеству является основным определяющим документом системы менеджмента качества и описывающим ее в соответствии с требованиями ГОСТ Р ИСО 9001: 2015 .

Общие требования к продукции в части установления технических параметров, санитарных норм и техники безопасности определяются ГОСТ РФ, а на каждое изделие разработаны и утверждены в установленном порядке технические условия, где определены конкретные значения качества продукции согласно технических регламентов.

В истории проблемы качества выделяются два периода. В течение первого серьезный интерес к тому, что есть качество, был ограничен в основном профессиональной теорией. Качество и его системное положение пытались определить философы, однако, и в многочисленных философских спорах понятие «качество» не принадлежало к числу главных проблем.

Актуализация теории качества оказалась в зависимости от степени разработанности системообразующего философского понятия «бытие» в контексте базовых производных от него понятий, т.е. тех понятий, которые помогают осуществить восхождение от предельно абстрактного утверждения существования с единственным отличающим свойством быть, существовать, к конкретному пониманию с устоявшимся содержанием, благодаря ответам на производные вопросы, такие, как «Из чего есть все?», «За счет чего все существует?», «Есть ли небытие?», «В каких системных формах бытие обретает свою определенность?» .

По-видимому, именно последний из перечисленных вопросов вывел философию на «тропу» того толкования качества, которое «зацепило» не только тех, кто «обустраивал» принципиально новый в человеческой истории тип мировоззрения.

Логично предположить, что проблема субстанции бытия, как первый шаг к теории качества, вряд ли кого волновал за пределами ограниченного сообщества философов. Всё свидетельствует о том, что интересно это было тем, чей взор был обращен в Космос, в глубины его конструкции, а подавляющее большинство земляков - философов находилось во власти земных проблем.

Для масс разнообразие и возможность выбора благ по существу были не доступны. Плебеи требовали: «Хлеба и зрелищ!». Праздником жизни во всем разнообразии ее проявления наслаждалась немногочисленная аристократия. Проблема качества жизни решалась в соответствии с социокультурной архитектурой общества. Проблема эта бесспорно имела место, но вызреть в актуальную для общества не могла. Причина проста - отсутствие достаточного уровня массовой востребованности качественного продукта.

Проблема качества обрела масштабы социальной актуальности в условиях перехода к экономике массового производства, демократизации общественных отношений, развития просвещения, доступности образования и других культурных ценностей. Чтобы вопрос о качестве сделался одним из наиболее важных для общества, нужно было, чтобы он стал актуальным для большинства тех, кто образует это общество. Без права на свободу и покупательской способности делать выбор, «качество» не способно быть среди приоритетов массового сознания. Элитные же запросы на качество разрабатываются в эксклюзивных, нетрадиционных теориях, главная цель которых не достижение истины, а удовлетворение потребности заказчиков.

Разумеетя, о качественных и количественных характеристиках явлений естественного и искусственного происхождения знали задолго до того, когда эти признаки актуализировались в общественном бытии и отражающим его развитие сознании, но, в свете нашего исследования, существование знания качества де факто не столь значимо. Предмет исследования не осознание качества, а развитие понимания качества на разных горизонтах общественной истории.

Развитие - универсальное состояние всего существующего от простейших материальных субстратов до высших форм мышления. Совершенствовались и качество, и количественное его выражение, прояснялась зависимость качественно-количественных изменений. Смещались акценты внимания с количества на качество. Доказав свою эволюционную прочность, человечество переключалось на принцип: «брать не числом, а умением». На смену борьбы за выживание пришло стремление к качественному уровню 
жизни в широком диапазоне толкования. Началась борьба за достойную качественную жизнь.

Как показывает история, уйдя от дикости и варварства, заложив основы цивилизации, люди заметно изменились во внешних формах своего проявления, но в недра человеческой натуры цивилизация проникает медленно и тяжело. Биологическая история заложила в природу человека активное начало, совмещенное с развитой способностью мышления, заметно превосходящей все иные виды отражения. Но вся эта надстройка сформировалась над достаточно жестким животным каркасом, подчиненным системной цели выжить в борьбе. Условия борьбы трансформировались, внося коррективы в средства и формы, однако сама природная база оказалась весьма инерционной.

Переход от естественного эгоизма биологического уровня к разумно-деятельному эгоизму, несмотря на известные цивилизационные средства культивации, не отвечал прогнозам ни романтиков, ни реалистовоптимистов. Цивилизация отметилась не цивилизационными формами отношений в движении к качественной жизни, чем еще больше актуализировала интерес к качеству. Чтобы стать в ряд с самыми важными проблемами, качество должно было предстать в нескольких функциях: как цель, как средство, как условие развития всех социальных субъектов на всех уровнях жизнедеятельности.

История для историков - события и участники, выстроенные во временной последовательности, своего рода хронология значимых фактов общественной и, отчасти, личностной жизни. Философ и специалист-не историк видят в истории свои интересы. Философский и специальный интерес к истории продиктован потребностью понять диалектику процесса применительно к деятельности человека. Специалист стремится обнаружить в прошлом тенденции пути решения своей проблемы, подчас далеко не частной.

Интуитивно еще на заре цивилизации термин история (historia) трактовался в смысле исследования искомого процесса в противоположность хронологическому описанию. У ионийцев повествование, рассказ о прошлом именовали логосом (logos). Лишь спустя время, уже в трудах основоположников философии логос приобрел современное значение - мысль, идея. И Геродот, и Фукидид понимали историю как осмысление хода, событий прошлого, необходимое для «наставлений в образе жизни» тем, кто живет в настоящем. Пройдя испытание временем, историзм укрепил свои позиции, стал идейной базой культурной памяти. Н.А. Бердяев утверждал: «От первых дней Творения...человек находится в историческом, и историческое находится в человеке. Погружение в глубь времен есть погружение внутрь себя».

Прошлое растворяется во времени, оставляя нам, наряду с памятью о былом, думы о настоящем и ответственность за будущее. Новое всегда относительно. Гете был прав, говоря, что все умное уже известно, надо только еще раз это продумать.

История - клад идей, золотая жила для мыслящего человека, чем бы он ни занимался. Различное отношение к истории есть совокупный результат действия двух причин: первая толкование времени, вторая - себя во времени. В дохристианский период истории время трактовали циклически, представляя его как сумму повторяющихся замкнутых на себя циклов. С христианством взгляд на время поменялся. Время предстало в качестве восхождения к бесконечному, разделившись на конечное земное и бесконечное внеземное. Противоположение циклического и внециклического рассмотрения времени характерно для теологической теории. Нас оно не интересует, впрочем, как и свойства времени в их абстрактном виде.

После Г. Гегеля и К. Маркса актуально не представление о чем-то вообще, а погружение в конкретно-предметное, либо конкретноисторическое состояние того, что оказывается объектом исследования. В случае со временем, актуально анализировать не столько его универсальные свойства, определять, куда и как оно движется. Важно то, что все существующее во времени может состояться, только соответствуя этим объективным характеристикам времени. Существовать во времени, значит обладать свойствами времени. Данное положение универсально и для бесконечного многообразия отдельных явлений, и для необходимо присущих им признаком бытия, к которым принадлежат «качество» и «количество».

Стандартное понимание закона перехода количественных изменений в качественные упрощает взгляд на их связь. И Г. Гегель, и Ф. Энгельс были далеки от того смысла, который распространялся под прикрытием диалектической теории развития. Количество в качество не переходит непосредственно. Новое качество, качественное состояние возникает как переход из предшествующего качества. В изменившихся количественных условиях мера исчерпывает резерв устойчивости функционирования.

Мера - «качественное количество», она указывает на пределы изменения количества без существенных последствий для данного качества явления. Выход количественных показателей, 
необходимых для достигнутого качества, за границы меры неизбежно влечет качественные преобразования. Одновременно с потерей прежнего качества идет процесс рождения из него, на его основе нового качества, соразмерного изменившемуся количеству. Ключевое положение во взаимоотношениях качества с количеством занимает мера. О мере же специалисты по качеству предпочитают всерьез не рассуждать, сводя меру к количественным стандартам. Будто мера - это какое-то проходное состояние системы «качество-количество». Надо четко понимать объективную и функциональную роль меры в управлении, как качеством, так и количеством .

«Мера» не принадлежит ни качеству, ни количеству. Она выражает системный способ отношений качества и количества, связывает их. Итак, первое: количество и качество взаимодействуют через меру, мера опосредует их связь. Какую «выгоду» извлечет из настоящего заключения специалист-практик? Массовое производство, включая «рачительную» его разновидность, требует мерной характеристики, в противном случае сказочный сюжет о горшке с кашей или «цветике - семи цветике» вполне имеет шанс реального продолжения. Китайский ширпотреб - классический пример разрушения диалектического единства в системе «количество-качество».

Рынок, по сути своей, не способен быть контролером меры, регулирующей отношения в системе « количество - качество». С приобретением оптовых форм развития, господствующего положения финансового капитала и его естественного порождения масштабных спекуляций и посредничества, современный рынок противопоставил себя производству и потерял интерес к состоянию производства. Рынок, используя специфику массового производства, насытился в меру своей извращенности и может позволить себе задавать качественные характеристики товаров].

Государство ведет себя на рынке, будто воспитатель в детском саду. Интересы рынка оно ставит выше интересов производителей и массового потребителя. Под «крышей» генеральной идеи - рынок тянет за собой производство, идет срастание рынка и государства. Качество -количественные оценки оказываются оттиснутыми в зону субъективного произвола.

До тех пор, пока теория качества системно не выстроена, теория управления качеством будет строиться на эмпирических началах, которые не в состоянии охватить предмет управления в целом, и относительно значимы в ограниченной специфике производства. За неимением ничего лучшего ими пользуются, экстраполируя локальный опыт на другие условия, получают эффект за счет добавленных мер по адаптации, к сожалению, опять-таки временный и частичный.

В калейдоскопе истории смены способов управления качеством можно различить определенную логику. Жизнь же требует не «определенной» логики, а логической определенности в форме целостной, системно обоснованной теории качества в качестве методологической опоры построения универсальных принципов теории управления качеством. Исходной здесь должна быть идея системности отношений «качество-количество» в рамках меры их сосуществования.

Раскрыться в полной мере качеству помогает количество. Качественную вещь можно создать и в одном экземпляре, но, чтобы раскрыться качественному потенциалу производителя, единственного экземпляра (или произведения) явно недостаточно. Фирма Фаберже обеспечила себе известность уже первым брендовым изделием, но брендом сделалась за счет последующих успехов в создании коллекции.

Примером системного понимания качества в рамках меры - мерной определенностью служат мелкие серии, выпуск коллекционных монет, медалей. Качество фиксируется в границах количественной величины, служащей мерой его выражения. Дело здесь не только в обеспечении условий преференции для vip-потребителя продукции. Значима также зависимость объективных признаков качества от количества произведенных экземпляров. Массовое производство объективно сопряжено со снижением качества продукции. Мера пограничная служба качества, переход за мерное количество есть преступление против качества.

Массовый отечественный производитель вряд ли интересуется теорией качества. Она для него не актуальна. Если все же случайно кто-то наткнется на наши рассуждения, то, вероятнее всего, улыбнется их наивности. Пытаться с помощью теории перестроить российский рынок, придать ему цивилизованный вид - классическое донкихотство. Сначала надо организовать рыночное пространство посредством политической воли, законодательных инициатив и действенного, а не бутафорского, контроля за узаконенным порядком, вернуть на рынок производителя товара, убрав немереное количество посредников - спекулянтов.

Настоящий производитель не заинтересован в спекулятивных операциях. Ему для устойчивого развития необходим свой потребитель, который, кстати, в свою очередь, совсем не против, иметь своего определенного и доступного производителя в рамках нравственно - правовых отношений. 
Чувство национального достоинства воспитывается историей и существующей реальностью. В школе можно учиться по самому лучшему учебнику истории, но кроме школьных уроков истории есть текущая жизнь, впечатляющая сильнее исторических экскурсов. На Востоке говорят: «сколько раз не повторяй халва, во рту сладко не будет». Теория всегда считалась лучшим практическим руководством, правда, в нормализованных обстоятельствах деятельности. Уходя в нелегальное и полулегальное положение, производитель отчуждается от качества и, естественно, от теории качества. Далее происходит подмена качества псевдо качеством и растут затраты на рекламную бутафорию.

Качество деятельности человека отражает такой комплекс еe характеристик, который в максимальной степени соответствует идеальному представлению об успехе.

Объектом управления является деятельность человека во всей совокупности ее факторов, характеристик и особенностей. Но любая деятельность человека представляет собой комплекс действий, направленных на решение какой-либо проблемы, позволяющей достигать поставленной цели.

Следовательно, можно говорить об управлении качеством как управлении теми характеристиками деятельности человека, которые делают эту деятельность такой, какая необходима для надежного и реального достижения цели.

Управление любыми процессами в итоге выливается в воздействие на определенные их характеристики: производительность, надежность, своевременность, дизайн, эффективность и пр. Комплекс таких характеристик отражает качество деятельности. Вот почему можно говорить об управлении качеством как об особом подходе.

В управлении существует ичель и средства ее достижения. Причем между этими двумя факторами устанавливаются вполне определенные отношения. Это отношения конкретности, взаимообусловленности, прямого взаимодействия, корректировки, гибкости, подстройки.

В большинстве случаев нашего отечественного управления качество рассматривается не более чем средство достижения цели. Если учесть, что цели, как правило, недостаточно определенны, то и средства их достижения обладают таким же свойством. Качество в управлении присутствует как общая характеристика выпускаемой продукции, достигаемая посредством нормативов, стандартов, технического контроля.

Мировой опыт управления свидетельствует об изменении статуса качества в системе и процессах управления. В стратегических планах многих фирм качество рассматривается как главная цель управления, которая определяет и прибыль, и имидж, и стабильность, и уверенность в конкуренции, и перспективность развития. Об этом свидетельствует хотя бы опыт Японии.

Современное управление требует постановки проблемы качества как цели управления, и достижение этой цели требует вполне определенных средств. В управлении качеством большое значение имеет понимание того, что качество не может быть достигнуто без учета всех его составляющих, без организации взаимодействия в системе управления по критериям качества. Во многих ранее создаваемых системах управления качеством главную роль играли характеристики продукции, свойства произведенного предмета, а не комплекс определенных характеристик, отражающих социально-экономический процесс функционирования и развития производства, качество социально-экономической системы вообще.

Качество продукиии есть следствие действия многих факторов - качества персонала, качества организачии производства, качества техники и технологии, качества управления, конструктивных разработок и пр. Все это кажется очевидным, тем не менее, в реальной практике управления качеством не стало еще особым типом управления.

Проблема качества в управлении должна иметь статус цели и предмета управления. Это трудно, но необходимо, потому что надо иначе подходить к определению содержания решаемых в управлении проблем, оценивать их по весьма сложным факторам. Качество продукции можно увидеть, оценить, понять. Но качество деятельности фирмы, дающей хорошее качество продукции, определить и оценить трудно, тем более оценить потенциал качества. Не все можно оценивать по конечному результату, не все одинаково явно включает в себя конечный результат. Многое как бы выпадает в процессе его производства, получения, трансформируется в другие свойства. Вот почему качество продукиии и качество деятельности - это не одно и то же, но последнее гораздо важнее для анализа управления, его организации, для постановки целей и ориентиров управления, выбора средств и методов управления.

Вот здесь-то и возникает и обостряется реальная потребность в системном подходе, а не просто в его декларации. В практической деятельности в самой постановке проблемы, в раскрытии ее содержания мы нередко исключаем саму возможность системного подхода к решению проблем. 
Не следует думать, что качество определяется только технологическими составляющими, есть факторы, которые выходят за пределы технологии. Это факторы культуры труда, эстетики производства, состояния рынка, общественного сознания, инфраструктуры производства и пр.

Системный подход в методологическом отношении предполагает учитывать не только то, что существует в наличии, в данной продукции, в готовом виде, но и то, что существовало в процессе ее изготовлении или формирования. Во многих случаях это были сложные и длительные процессы, в которых что-то исчезает, превращается в нечто иное, что-то меняет статус. Но ничто не проходит бесследно, и все остается в той или иной мере в качестве. Тем и ценно само понятие качества, что оно ориентирует на системный подход, если рассматривается как цель управления, что оно требует учитывать факторы процессуальности и структуры, существования и развития, факторы соответствия определенной внешней среде, интересам человека, ценностям общественной жизни и пр.

Сегодня для управления качеством необходимы не только стандарты и государственные требования к качеству. Они могут отражать лишь минимальный уровень качества, которое должно защищать государство. Вообще государственные требования к качеству - это система административного управления качеством .Никакие стандарты и государственные требования не смогут успевать за меняющимися интересами человека, рыночными процессами конкуренции, за изменением системы ценностей и образа жизни. А ведь именно они и определяют понимание качества и необходимость гибкого, социальноэкономического управления качеством.

Качеству необходимы критерии, отражающие динамику социальноэкономических процессов. Качество должно определяться рыночными ситуациями, характеризующими процессы динамики спроса и предложения, потребностей и ценностей. Ведь только рынок посредством механизмов спроса и предложения, конкуренции, ценообразования и других процессов может показать истинное качество продукта, показать, что надо учитывать в его характеристиках. Государственные требования, если они должны быть, могут гарантировать лишь минимум качества, посредством которого строится система защиты потребителя от совершенно недоброкачественной продукции. Настоящая динамика качества может быть понята только по экономическим показателям спроса и потребления, конкуренции, цены, функционального назначения продукта, его влияния на образ жизни и роль в изменении образа жизни человека.

Качество - это не только совокупность свойств продукта, это и инициатива и активность производителей в достижении этих свойств, в поиске и достижении их определенной комбинации.

Качество - это понятие социальноэкономического типа, это не статичная система свойств, это отношение человека к своему труду, к обществу, к управлению.

По показателю присвоения Знака качества мы всегда находились в состоянии роста. Но истинную динамику качества мы чувствовали вопреки этому показателю. Возникает естественный вывод, что - либо занижались критерии, либо просто неправильно составлялись и использовались эти показатели. Знак качества не показывал истинного качества. Об этом можно судить хотя бы по экспорту продукции. Объем продукции со Знаком качества у нас рос, а спрос на нашу продукцию на мировом рынке снижался по причине плохого качества, его несоответствия мировым стандартам.

Сейчас происходят процессы структурной перестройки нашего производства, и очень важно заложить в систему управления принципиально новые основы управления качеством, ориентировать производство на качество как цель управления и основу успешного функционирования производства.

Качество - это тип развития, это новые подходы к регулированию циклов жизни продукции, созданию новых видов продукции, оценке морального старения и физического износа, учета принципа универсальности.

Управление качеством требует и соответствующей этой цели системы информационного обеспечения. Опираясь только на скудные данные отечественной отчетности, нельзя подчас составить истинную картину состояния качества, тем более найти причины его изменения или оценить процессы формирования. А ведь главное в управлении это истоки качества и тенденции его изменения.

В традиционном представлении проблема управления качеством сводится главным образом к проблеме контроля качества. Это признак и фактор административного подхода к управлению качеством. Но опыт, как отечественный, так и зарубежный, показывает, что главным фактором управления качеством является комплексное мотивирование качества, при котором ведущую роль играет не контроль, он может быть сведен к минимуму, а образ деятельности производственного работника, в котором соединяются и функции, и цели, и средства самоутверждения, и интересы, и отношение к фирме, и коммуникабельность, и 


\begin{tabular}{l|lr|ll|ll} 
& ISRA (India) & $=\mathbf{1 . 3 4 4}$ & SIS (USA) & $=\mathbf{0 . 9 1 2}$ & ICV (Poland) & $=\mathbf{6 . 6 3 0}$ \\
Impact Factor: & ISI (Dubai, UAE) $=\mathbf{0 . 8 2 9}$ & PUHЦ (Russia) $=\mathbf{0 . 2 0 7}$ & PIF (India) & $=\mathbf{1 . 9 4 0}$ \\
& GIF (Australia) & $\mathbf{0 . 5 6 4}$ & ESJI (KZ) & $=4.102$ & IBI (India) & $=\mathbf{4 . 2 6 0}$ \\
& JIF & $=\mathbf{1 . 5 0 0}$ & SJIF (Morocco) & $=\mathbf{2 . 0 3 1}$ & & \\
\hline
\end{tabular}

социально-экономическая деятельности.

Управление должно быть ориентировано именно на образ деятельности, соответствующий определенному типу качества деятельности.
Это в итоге дает качество продукции и без жесткого контроля административного типа, а контроля как системы аналитической оценки.

В рыночной экономике «знак качества» это цена продукции, ее известность, спрос, имидж фирмы, которая недоброкачественную продукцию вообще выпускать не может.

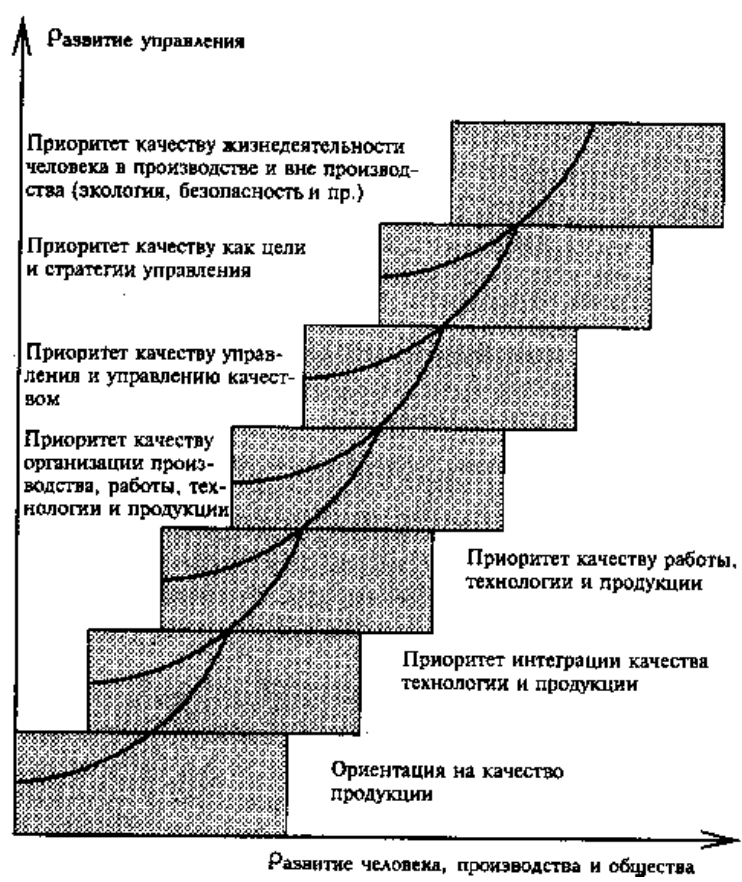

Рисунок 1 - Изменение приоритетов и роли управления в достижении качества, семь шагов в будущее

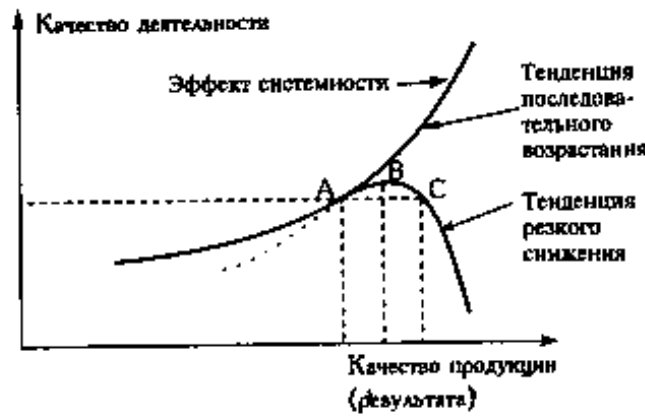

\section{А - точка необходииого переключения приоритет. \\ В - точка упуценных возиожностей в росте качества продукции}

C - точка тендеңции на снижение качества

Рисунок 2 - Качество деятельности и качество продукции: тенденции взаимозависимости

Достижение определенного качества требует затрат. Величина затрат на качество важнейшая характеристика, отражающяая управление качеством. Но затраты на качество еще не характеризуют потенциал достижения качества. Могут быть затраты очень высокими, но качество низким, потому что затраты невсегда имеют непосредственную и прямую отдачу. Они иногда служат лишь последовательному формированию потенциала качества, например затраты на квалификацию работников, инфраструктуру производства.

Поэтому в управлении качеством большое значение имеет формирование потенциала качества, который включает культуру деятельности, социально-психологическую 
атмосферу, квалификацию и образование работников, технологию, техническую вооруженность, тип организации деятельности.

Качество действительно предполагает серьезные затраты, но оно гарантирует устойчивую рыночную позицию. Работая на качество, производитель создает уверенность в своем и национальном будущем. Правильно выстроенное понимание качества гарантирует перспективу даже в условиях отечественного полу рынка].

Постараемся в порядке введения в теорию качества сформулировать практически значимые фундаментальные положения:

Качество не сводится к сумме важных для бытия товара свойств; оно - их своеобразная комбинация, выстроенная на базе обычно двух признаков - более общего и более специфического. К примеру. Обувь - «одежда для ног», шляпа - «одежда для головы», кашне «одежда для носа и шеи» и т.п. Следовательно, центральное внимание нужно уделить именно им.

Качество допускает изменения, не ведущие к утрате качества, но снижающие или повышающие его потребительскую ценность; качество - совокупность качественных состояний, удовлетворяющих в разной степени системообразующим признакам. «Люфт» качества позволяет маневрировать в процессе создания продукта с заданным качеством в зависимости от конкретных возможностей производителя и потребителя.

$\square$ Качество не существует вне количества, они - диалектические противоположности, их противопоставление действительно только в пределах единства, из чего следует, что, создавая качество, необходимо закладывать в качественные характеристики количественные выражения как в отношении отдельных свойств товара, так и количества товарных изделий. А.К. Саврасов, оказавшись в тяжелой жизненной ситуации, сделал несколько копий своей знаменитой картины «Грачи прилетели». Как правило, авторские копии имеют высокий уровень мастерства и за них хорошо платят. Заплатили и художнику. Когда же задали вопрос П. Третьякову: купил бы он копии картин художника А.К. Саврасова, случись что с оригиналом? Ответ П. Третьякова оказался прогнозируемым по категоричности - нет! Качество требует не только мастерства, но и вдохновения. Вдохновение с повторами выгорает. Качество всегда количественно, а количество - качественно.

$\square$ Качество и количество связывает мера, о которой чаще всего забывают. Между тем, определяя качество, нужно одновременно думать о его мерности, и с позиции рыночной конъектуры, и с точки зрения самих признаков качественности. «Качество» конкретизируется в представлении о «качественности». «Качество» понятие, отражающее модельный образ товара, «качественность» - определяет количественные пределы действительности и разумности качества (физического и морального статуса товара).

Качество и представление о качестве относятся к явлениям устойчивым, однако время изменяет и их. Первоначально качество отождествляли со значением. Критериями качества были полезность и величина предмета, отношения. С развитием сознания и практических возможностей сложились основания сравнения и выбора. Качество относительно обособляется от количества. Совершается дифференциация полезности, переосмысливается участие в качестве количественных признаков. Эволюция понимания качества непосредственно обусловлена воплощением в деятельность творческого потенциала. Расхождение в интенсивности продвижения вперед индивидуального мастерства, интересов тех, кто призван расчищать путь таланта и массового сознания усложняет понимание качества и процесс управления качеством. Особое значение приобретает конкретность толкования качества, в частности, такого его базового признака, как объективность. Общественная теория бытия выстраивается на естественно исторической основе - канву ее заложила природа, а исторический рисунок сотворил человек. В естественной среде все признаки, включая и такие синтетические, как качество - продукты стихийного движения. В обществе всякое явление проходит через деятельность, включает в себя и в свое качество мыслительный и физический труд человека. Определение качества явлений, созданных человеческой деятельностью, невозможно без социокультурной конкретизации. В связи с чем, актуализируются два вопроса:

в каком статусе и в какой мере сознание входит в то, что традиционно принято называть качеством вещей (с услугами ясности больше)?

Ответы на оба вопроса надо искать в философской теории отчуждения. Теория отчуждения прямого отношения К теории качества не имеет. В ней ключи к методологии построения теории качества. Из выше расположенных рассуждений понятно, что авторы - не идеалисты, скорее балансируют на грани пессимизма и оптимизма. Они критично воспринимают современный прогматизированный подход либераловрыночников к научной и философски обоснованной теории. Облегченный вариант теории, когда вырванный из общей теории фрагмент превращают в самую теорию и подгоняют под конструкцию извращенного в 
угоду спекулянтам рынка, экономистовтеоретиков и поставщиков качественного суррогата на отечественные прилавки устраивает. Как долго российская экономика сохранит подобную конфигурацию, нам (и не только нам) знать не дано, однако мировой опыт экономического развития на различных стадиях экономических отношений свидетельствует, что переходные периоды проходят и со временем экономическая жизнь приходит в нормальное состояние.

Траектория процесса отчуждения творчества человека в то, что существует вне его, должна с необходимостью сохранять и активировать способность к созиданию. В отличие от бытия природы, бытие человека не субстанционально. Оно не самодостаточно и может иметь место исключительно благодаря взаимообмену изначально с природой, в последствие с обществом, через которое выстраиваются человеческие отношения друг к другу и взаимодействие с природой. Инструмент, обеспечивающий бытие человека - труд, высшее качество труда проявляется в деятельности.

Качественность деятельности, с одной стороны, показатель качества жизни человека (так должно быть!), с другой - качественная деятельность встраивается в качество того, что он преобразует. Качество «первой» (естественной) природы формируется само по себе как совокупность объективно связанных естественных признаков, стихийно. Качество «второй» (реконструированной, приспособленной человеком под свои интересы) природы синтетическое. Оно представляется двойной спиралью, образуемой естественными признаками природного материала (возможно - в отношениях людей, знаниях, выраженных опосредованно) и качественными характеристиками человеческой деятельности знаниями, эмоциями, волей, ценностной ориентацией, мастерством. В итоге качество продукта в отличие от самого продукта воплощает качество личности.

Личность отчуждается в качестве и потому, в принципе, отчуждение естественно и не угнетает личность. Негативное следствие отчуждения вызвано непропорциональностью возмещения утраченной энергии деятельности. Обнаружив не качественность товара, скрытый брак производства, обманные действия продавца, нормальный покупатель расстраивается, в первую очередь, из-за собственного некачественного решения. Иные убытки сделки чаще всего возмещаются. Остается ощущение несовершенства собственного вкуса и знаний.

Качество всего, что создано деятельностью, включает свойства деятельности, как практической, так и духовной в объективированном (предметном либо функциональном) выражении. Отсюда следует вывод о необходимости формировать и направлять развитие способности массового сознания к качественной оценке товаров: определенный опыт в советское время был и показал свою действенность: «кружки», «школы», «университеты», в том числе инициируемые телевидением и радио. Место системного просвещения массового потребителя, профессиональной помощи в развитии культуры качественной избирательности, сегодня в эфире забито агрессивной рекламой, качество которой не контролируется или контроль не соразмерим с размером обмана. Кто должен быть главным просветителем? Производитель и только он, ибо лишь ему в полной мере, по логике становления понимания, следует знать, что такое качество. Браться за производство товара, не осмыслив конкретность качества данного изделия, означает профессиональный провал на рынке.

Выпуск же продукта с бутафорским качеством преследуется законом, правда, формально и постфактум. На последнее и надеются поставщики псевдо качественных товаров.

Объективности ради скажем: истинные творцы качественной продукции будут на нашем рынке изгоями до той поры, пока блюстители порядка уверенны в собственной безнаказанности за коррупционную деятельность. Тем не менее, идти вперед необходимо. История уродливо, но все-таки движется к порядку консервативностью техники изготовления, но и в тот период муниципальные власти жестко проверяли качество изделий, равно как и способности кандидата в производители, действовало официальное положение, одобренное властью города или страны. Сельхозпродукция контролировалась самими потребителями.

Промышленная революция упростила процесс производства, создала условия массового производства. Потребовались адекватные меры контроля качества. По мере выравнивания социальной архитектоники и большей доступности к ассортименту товаров, менялись представления о качестве в направлении его качественности - качественных составляющих. Одновременно формировалась возможность фальсификации качества. Дальше и де-факто и де-юре, оставался всего шаг до подмены брендовых качеств. Переход за границу меры открывает дорогу правовым нарушениям и нравственному кризису, вплоть до без предела .

Тенденции в толковании качества и отношении к качеству, сложившиеся в экономике массового производства, были неизбежными? Нет, они порождались новым характером производства, отражали этот характер и в 
известной степени являлись объективным отражением, но, кроме предмета, отражаемого сознанием, существует ракурс отражения, обусловленный позицией сознания отражающего субъекта, его интересами в качестве участника процессов, происходящих в объективной реальности.

Сама объективная реальность, по определению, располагается вне и не зависимо от сознания. Субъективируется ее отражение, что, в общем, выглядит в согласии с теорией отражения. Однако допускает, в частном порядке, и субъективное искажение - непроизвольное - по недопониманию, и сознательное с целью получения временного выигрыша. Конкуренция всегда борьба, к сожалению, борьба не всегда ведется по правилам.

Качество было и остается предметом манипуляции в интересах тех, кто управляет рынком. Консенсус о качестве создателя, производителя, продавца и потребителя - самая сладкая сказка. Согласие достижимо между творцом, потребителем и производителем. В данной «троице» воплощен субъектный механизм разрешения проблемы отчуждения. Творец создатель продукта находит удовлетворение в производстве и потреблении. Он реализует в них свою человеческую силу. Производитель заинтересован в устойчивых отношениях с творцом и потребителем. Потребитель удовлетворен качеством и соразмерностью цены. «Акции» и «sale» его не путают и не обманывают.

Прежнее управление качеством, хоть и имело такое название, обладало следующими недостатками:

1. Оно осуществлялось в условиях административного управления и поэтому несло отпечаток этого управления (административные методы регулирования качества, ограниченные возможности мотивирования высокого качества, опора главным образом на систему контроля качества, планирование качества и тем самым ограничение его улучшения).

2. Качество в процессах управления рассматривалось как средство достижения определенных целей (выполнение преимущественно количественных показателей плана).

3. Качество декларировалось очень широко, но не было фактором механизма управления, призыв к качеству не подкреплялось дополнительным финансированием.

4. Главным в понимании и регулировании качества было качество продукции. Отсюда все действия по повышению качества и его анализа начинались с продукции и были привязаны к ней. Такова методология управления , таков подход к управлению качеством: учитывать только то, что непосредственно влияет на качество продукции, и оценку ее качества делать по плановым показателям. Это был ограниченный подход.

Обозначим новые подходы к управлению качеством.

1. Качество должно войти в процесс управления как цель, определяющая все необходимые средства ее достижения. Разница в том, что цель направляет развитие, а средства обеспечивают целенаправленность процессов, возможность достижения цели. Качество - это то, к чему надо стремиться, а не то, что выступало бы инструментом или методом какихлибо достижений иного характера.

2. От ориентации на качество продукции надо переходить к ориентации на качество деятельности. Это требует расширить круг факторов, включаемых в методологию анализа проблем, их постановки и поиска. Это означает понимание того, что качество продукции определяется качеством жизни, именно оно показывает, какое качество необходимо, достижимо; это означает, что качество продукции надо рассматривать в ракурсе качества жизни. Это свидетельствовало бы о подлинно человеческом факторе управления.

3. Управление качеством должно опираться на рыночные механизмы экономического развития. Это означает, что не следует стремиться управлять качеством на основе требований. Главное - это экономическое мотивирование качества, как в целом, так и в мелочах, обеспечение его достижения, исследование качества.

4. Методология управления качеством предполагает системный подход. Это означает, что в управлении качеством главным становится выявление всех скрытых и явных, прямых и опосредованных связей факторов, влияющих на качество и формирующих качество и назовём практические рекомендации по управлению качеством:

1. В работе с персоналом надо уделять внимание не только его квалификации, но и качеству образования.

2. Не стремиться предъявлять требования к качеству продукции или даже к качеству работы, но стремиться повысить активность по отношению к качеству, искать пути улучшения качества на каждом рабочем месте, формирования качества, как в мелочах, так и в целом.

3. Необходимо найти главное в процессе формирования качества деятельности. Оно различно для различных фирм, но оно всегда существует.

4. Не стандарты и требования решают проблему качества, а люди, заинтересованные в повышении качества. 
5. Качество - не только и не столько характеристика выпускаемой продукции, сколько социально-экономическая характеристика деятельности. Надо стремиться не только к качеству продукции, а главным образом к качеству деятельности, потому что это закладывает потенциал качества даже тогда, когда первоначально не отражается на качестве продукции.

6. Качество деятельности - это не просто производительность труда, это осознание деятельности, культура, отношение к деятельности, профессионализация, образование, позволяющее иным образом использовать профессиональные навыки.

7. Стремиться к качеству деятельности - это значит не только хорошо работать, а стремиться к самосовершенствованию, самообразованию.

творчеству,

На пути к консенсусу встает продавец, тот субъект отношений, который, по существу, к качеству товара не имеет никакого отношения, но именно он - ключевая фигура в рыночном хозяйстве. Мы у него приобретаем все необходимое. Он - монополист и как таковой диктует условия отношений через ценовой интерес и размер прибыли. В России за двадцать лет не появилось ни одного брендового предприятия легкой промышленности, напротив, объявилась масса торговых брендов. Торговые ряды множатся, а потребителя уверяют, что производство товара нерентабельно. Культуру организации торговли подменяют понятием «качество продажи». Культура торговли измеряется ассортиментом, ценовой и физической доступностью товара, качественным консультативным сопровождением, отсутствием очередей, соблюдением санитарно-гигиенических норм, внешним видом и поведением персонала, сервисным обслуживанием. «Качество торговли» определяется соразмерностью цены и качества товара, соответствием продаваемого товара его сертификату, демонстрацией товара. Размер прибыли продавца не должен превышать величину прибыли производителя. Обоим нужно не ждать повышения покупательской активности только за счет увеличения зарплат потребителей, а создавать режим наибольшего благоприятствования для покупателя (не вступая в сговор с еще одним хищником рынка банками) .

Только в России и только либералы рыночники при каждой возможности вспоминают, как плохо было народу до наступления подлинной демократии - голодали, ходили оборванцами, жили неизвестно где и как. Мониторинг качества жизни - через качественные возможности потребления целесообразен в рамках существующего времени.
Критерий один - растет потребительская корзина и за счет чего она увеличивается?

Размер инфляции - необходимый, но не достаточный показатель состояния качества жизни. Правительство за основной ориентир взяло снижение инфляции. Показатель на самом деле социально - экономически значимый, свидетельствует о культуре рынка и опосредованно о состоянии производства. Минус этого показателя - отсутствие в нем качества. Качество жизни определяется через количество потребляемой продукции в денежном выражении. Качественный состав остается постоянным и о качественности можно лишь домысливать, так как качественность размывает качество. Качественность обуви, одежды, круп, рыбы, овощей, фруктов в пределах общего названия весьма существенно разнится. Резерв манипулирования качеством значителен. Главное все же в понимании качества, не название, а системная характеристика продукта, отражающая ассортимент, его изменение и динамику пропорционального представительства составляющих совокупность товаров.

Качество представляет систему существенных для товара свойств - это банально и общеизвестно, чем активно пользуются. Подменяя свойства либо их системность в качественном продукте. Существенные свойства - те, которые не просто присущи товару, они обусловливают его функциональность. Подобные свойства, как правило, раскрываются в процессе «работы» товара по назначению, они скрыты от непрофессионального взгляда потребителя. В «чистом» виде рынок - посредник и к качеству изделий не должен иметь интереса. Задача рынка в теории организации товарного производства организация обмена между производителем и потребителем. Развитие рынка стимулирует наращивание производства в интересах потребителя в пределах инфраструктурного статуса рынка.

Монополизация производства привела к накоплению финансового капитала, автономизации последнего и контролю за рынком. В результате рынок из посредника превратился в ключевого субъекта, индикаторную функцию - показывать востребованность товаров - пытается подменить ролью организатора экономической деятельности в целом, что извращает систему экономики.

Экономику товарного производства создали производство продукта и потребность в массовом продукте. Системообразующим фактором здесь является производство товара в качестве продукта, необходимого для потребления другими, то есть процесс отчуждения потребления. При натуральном производстве качество продукта вряд ли было актуальной 
проблемой. Качество «растворялось» в консерватизме техники и технологии, традиционности ассортимента. Вопрос о качестве поднял потребитель, когда на ярмарке получил возможность сравнивать. Рынок, выросший из ярмарочных сходов, представительский статус постепенно обогатил рекламным бизнесом, взяв в управление отношения производителя и потребителя. Рычаги управления - финансовая политика, направления - основные - два: влияние на количество и качество.

Качество продукта обрело актуальность в товарном производстве. Стало ясно, что в понимании качества присутствуют чувственное и рациональное мышление (последнее в форме расчета). Субъективный фактор объективируется и фетишизируется. На объективные свойства товара рынок непосредственно (с помощью собственных механизмов) воздействовать не способен, зато на объективизацию субъективных представлений очень даже может. Так манипуляция качеством сначала включалась в функции рынка, потом стала элементом экономической политики.

Здравая и здоровая экономическая политика призвана работать над совершенствованием качества в двух взаимосвязанных направлениях: технико-технологическом, достроенным жестким правовым блоком обеспечения, и социокультурном - оказывать всестороннюю поддержку становлению условий субъективного восприятия качества, блокировать негативный эффект рекламного воздействия, давно и основательно ставшего атрибутом рыночных спекуляций на значимости качества для покупателя. Наличие выбора и платежеспособных возможностей не служат основанием бесспорности качественного приобретения.

На существующем рынке цена и качество разведены даже на аукционах, славящихся тщательностью организационной культуры. Покупателя превращают в эксперта и эта гримаса рынка не столь плоха, как нелогична. Рынок заставляет потребителя развиваться в качестве личности. Из обывателя с кошельком мы, чтобы не оказаться лохами, невольно стараемся больше узнать о предмете интереса, повышаем свою «покупательскую квалификацию». Термин не новый, им пользуются журналисты, но для них он проходной, вербальный номер, а для нас уже не новое сочетание расхожих слов, а важнейшее понятие, без которого современная теория качества не имеет системного целостного вида.

«Покупательская квалификация» включает, наряду с определенными знаниями, помогающими определить местоположение магазина, диапазон цен на товар, требует наличия основных сведений о производителе, качественных признаках товара, рыночной репутации производителя, традиций фирмы, масштабов деятельности. Сегодня на потребительском рынке наивный покупатель рискует сверх всякой позволяющей меры оказаться жертвой не только обмана, но и собственной беспечности, следовательно, без каких-либо прав на компенсацию.

Покупатель в России защищен формально. В реальной жизни приходится руководствоваться знаменитым правилом «спасение утопающих («покупающих») - дело рук самих утопающих, читай «покупающих».

Повышение «покупательской квалификации», при наличии желания, для государства взаимовыгодное дело, активизирующее культурное национальное наследство и патриотическое настроение массового потребителя. Хотя есть и путь иной, испытанный при Мао в Китае - «чем хуже, тем лучше».

Импортный ширпотреб - не китайский - в 1980-90-е гг. был у нас на ура! Впечатляли ассортимент, упаковка, внешние признаки продукта. И что в итоге? Спустя 10 лет производитель возвращает советские бренды, естественно в отсутствии действенного контроля, не советского качества.

Мы умеем делать качественные изделия и вполне в состоянии вернуть себе «наш» рынок. Вопрос даже не в цене, проблема в потере контроля за потребительским (и не только потребительским, судя по сбоям в ракетной технике, эксплуатации авиатехники и т.п.) рынком. Нам объясняют: нужны экономические меры. Правильно, однако, это полуправда. Если нужны, то принимайте. У власти должна быть власть не номинальная. Пришло время понять, что экономика всегда была политикой, экономическая теория - политической экономией.

Экономическое движение есть самодвижение, но оно не в вакууме происходит. Экономика - основа общественного движения. Общество обеспечивает условия экономического движения, и государство вправе энергично включаться в механизмы экономического самодвижения, направляя развитие экономики в интересах общества.

Удивительное дело. Когда речь заходит о будущем технического прогресса, то футурологи разных мастей стонут, что автономизация движения техники приведет к господству роботов над человеком, а в развитие экономики лучше не вмешиваться. Для кого лучше? Вывод напрашивается один: не нарушать самодвижение экономики в интересах тех, кто приватизировал экономику и на чьей службе находятся 
«пограничники», запрещающие контролировать экономические процессы посредством политики.

Ни одна из конвертируемых валют не обеспечена качественным товарным эквивалентом и «свободное» движение валюты продолжается под прикрытием политики. Финансовое самодвижение создает благоприятные возможности для хаоса на потребительском рынке. Государство вяло защищает законные интересы национального производителя, даже тогда, когда товар - продукт межнациональной интеграции. Нет политической агрессивности, политика тащится в обозе экономики вместо то, чтобы опережать ее развитие на базе объективных социальноэкономических тенденций. Хочется верить объяснениям политиков относительно успешности вступления в ВТО. Хорошо, что они торговались, создавая правовую «подушку безопасности» для отечественного производителя товаров массового потребления. Проблема: как они уступками со стороны ВТО теперь воспользуются?.

Время для политического действия - не решений - самое благоприятное. Дурман девяностых и нулевых как будто пошел на спад. Возвращается осознание качественного преимущества многих советских продуктов легкой и пищевой промышленности. Наблюдается оживление в потребительской кооперации, что способно стимулировать производство сельхозпродуктов на селе. Растет недоверие к потребительскому импорту, в том числе и по причине его массового китайского производства. Стабилизируются миграционные потоки.

Жесткая оценка социально-экономической ситуации и прямое указание на ответственность правительства за неисполнение президентских поручений 2017 г. в Послании В.В. Путина, ассоциируются с решимостью «закручивать гайки», чтобы движение шло по намеченному курсу. Явная активизация в межнациональных экономических отношениях внутри Таможенного союза, перезагрузка стратегических отношений с акцентом на Китай, Индию, Иран, Латинскую Америку. Реальная возможность полномасштабного сотрудничества с Египтом, Сирией и тем же Ираном - ключевыми государствами Ближнего Востока и африканского севера - все это уникальная международная сфера для восстановления баланса на внутреннем рынке потребительских товаров.

Отечественным производителям нужна «внятная» экономическая политика. Под «внятностью» они понимают: ясность, последовательность, гарантийное сопровождение, позволяющее отсечь многоликий произвол административных органов власти и «блюстителей» порядка. За качество отвечают все. И те, кто производит, и те, кто призван обеспечивать права производителей. Таможенный Союз зажег зеленый свет на пути национальных товаров на рынке стран Договора. Тем самым создана равновесная реальная рыночная конкуренция, позволяющая оценивать натуральное, а не рекламное качество. Кстати, замечательная тема исследования - «качество реальное и «рекламное», т.е. создаваемое рекламой.

Не менее актуально и проанализировать проблему качества в системе координат национального менталитета и межнациональной интеграции. Интеграция сознательно подменяется глобализацией, несмотря на очевидность в различии этих явлений. Обе тенденции объективны и характерны для новейшей истории.

Интеграция

межнациональное взаимопроникновение различных видов деятельности социально - экономического и культурно-гуманитарного масштаба. Она может иметь межнациональный размер, пример «Союзное государство (РФ и РБ); локальный Таможенный Союз; региональный (Шанхайская организация, ЕЭС). Глобализация указывает на всемирный масштаб явления. К числу глобальных проблем относятся те, которые возникли как следствие общих, но не обязательно интеграционных, процессов, и требуют консолидированного решения.

Глобальные проблемы, в отличие от проблем, связанных с интеграцией, актуальны потенциально, носят стратегический смысл. К примеру, как защитить жизнь на Земле от крупных метеоритов. Когда время наступления события отложено, но само оно сверх актуально по значимости, то в образовавшийся зазор активно устремляются спекулянты, в том числе финансовые олигархи, пытаясь извлечь прибыть из неопределенности.

Качество связано с глобализацией, но практически не так актуально. С интеграцией же качество связано самым непосредственным образом.

Рассмотрим проблему «качества потребительского товара» в системе координат «национальное» и «межнациональное». Прежде всего, надо найти ответ на вопрос: способна ли интеграция вытеснить национальную составляющую качества?

Интеграционные процессы строятся на стандартизации и единых метрологических характеристиках производства, что соответствует объективной реальности. Технический прогресс опирается на науку, научные знания императивны в части нормативности. Однако бытие общего не самодостаточно. Общие 
требования реализуются через особенное развитие, обусловленное конкретностью обстоятельств действия. Иными словами, как бы стандартизировано производство товара не было, все равно в нем проявится своеобразие условий производства.

Конкретность условий - региональных, национальных имманентно присутствует в сырье, климате, традициях, культуре сознания исполнителей. И во всем этом сила производства, определяющая нюансы качества товара, создающие особый к нему интерес потребителя. Чай выращивают в наше время по всему миру, но уникальность чайных плантаций в Шри-Ланке, национального отношения к чаю, обеспечили качеству цейлонского продукта лидирующие позиции. Тоже самое можно сказать о кенийском кофе, болгарском и чилийском перце, французских коньяках и шампанском, украинском сале, баварском и голландском пиве, шотландских виски, российском льне, египетском хлопке, китайском шелке, аргентинской коже, греческом оливковом масле и многом еще. Конкретностью среды следует дорожить и обеспечивать преференции еѐ воспроизводства. В основополагающих договорах, регулирующих отношения в Единой Европе, четко прописан приоритет национальных традиций.

Таможенный Союз закрепляет межнациональное разделение труда, выстроенное в XX столетии, способствует выражению объективных и субъективных сторон развития производства, взаимно обогащает рынок, облегчая доступ к нему производителей. Но все это - теория. Теория же перерастает в разумную практику не только потому, что она правильная. Практикой теорию делает деятельность, причем, чтобы получить искомый результат, деятельность должна быть системной и последовательной.

Интерес к качеству товара, теоретически должен начинаться не в производстве. Его исходная позиция на нормализованном рынке, точнее на встрече производителя и покупателя. Нормальный рынок - индикатор качества товара. Спрос тянет за собою производственную цепочку. Но не стихийный спрос брошенных на произвол судьбы покупателей. Спрос - состояние сознания, обусловленное покупательской способностью, однако не сводимое только к количеству денег, тем более, когда кредитование всячески стимулируется банками. Спрос, отданный на откуп посредникам, лоббистам, спекулянтам - смертельная болезнь для национального производителя России. Спрос следует брать под контроль и формировать, покупателя нужно воспитывать. Воспитание потребителя стоит немало. Но оно этого стоит, если смотреть в будущее.

\section{Заключение}

Рыночный либерализм соответствовал расцвету экономики массового производства первого типа, ориентированной на обеспечение свободного доступа и выбора товаров. Подобное производство воспринимает потребителя как абстрактного субъекта отношения в системе «производитель - продавец - покупатель». Продавцу отводится роль активного посредника, но не более того. Он культурно обеспечивает место встречи производителя с потребителем. Система же должна быть функционально активной, что предполагает не присутствие образующих ее компонентов, а их соучастие. Совершенство системы определяется не эстетичностью - признаком конструкции. Оно проявляется в максимальной активизации возможностей того, системой отношений чего она выступает. Совершенство конструкции системы - в предельной реализации потенциала отношений, создающих системность.

Покупатель совершенен как субъект системного взаимодействия своей покупательской подготовкой. Он совершенен не размером платежной способности. Его соучастие определяется знанием товарно-экономической ситуации. Потребитель - не объект приложения действий продавца и производителя. Потребитель - субъект рынка и в его (и других субъектов тоже) интересах быть информированным не рекламным сообществом, а профессиональными источниками. Тогда контрафакт и «лохизм» перестанут заселять рынок. Качество товара начинается в сознании потребителя. Навязывать представление о качестве - плохо для всех законных субъектов экономических отношений. Его нужно воспитывать опять-таки всеми: производителем, продавцом, самим покупателем и институтами гражданского общества, если государство пассивно.

Переход к массовому производству второго типа - «умной», «рачительной» экономике активирует системные отношения. В новом свете предстает функция рынка. Вместе с производителем, продавец ориентируется на знание потребительских вкусов. К совершенству системы остается сделать всего один, однако не простой, шаг - всем миром взяться за формирование потребительской культуры.

Обвинение нынешнего поколения в потребительском отношении к жизни не совсем справедливо. Потребление - конечная цель производства. Беда - в отсутствии потребительской культуры массового потребителя, беда действительно социокультурного размера. Еще одно последствие финансирования культурного прогресса. Почему одна власть сменяет другую, а 
культура по-прежнему у власти последняя в очереди на политическую актуальность? Время понять, что не только наука превратилась в непосредственную производительную силу.
Культура - также фактор развития производства, причем, фактор многогранный и весьма эффективный.

\section{References:}

1. Prokhorov V. T., Maltsev I. M. (2004) Software for screening factors in the active conduct of the experiment. The program for computer №2004611762729. Registered in the Register of computer programs 26.07.2004

2. (2007) The software to solve the problem of non-stationary processes of heat exchange systems of the "Stop - footwear environment", provided the dependence of conductivity on temperature: the certificate of official registration of computer programs № 2008610087 / Mikhailov A. B. Was 09.01.2008. - Registration in the register of computer programs. Application No. 2007614069 (17.10.07).

3. (2009) Software the task of assessing the comfortable stay of man in shoes depending on the changes in heat flux stop time-a certificate of official registration of computer programs №2009613371 / Aspen T. M. Was 26.06.2009. -Registration in the register of computer programs. Application No. 2009611957 (29.04.09).

4. Aspen T. M., et al. (2011) the Certificate of official registration of computer programs №2011611394. Software for calculation of the temperature field of the unsteady heat transfer process in the "Stop - footwear - environment" when exposed to stop low temperatures. Issued by the Russian Agency for patents and trademarks (ROSPATENT) 11.02.2011 g.

5. Aspen T. M., et al. (2011) the Certificate of official registration of computer programs №2011619212. Software description the local unsteady heat transfer in the system of "Stopfootwear-environment" for different climate zones". Issued by the Russian Agency for patents and trademarks (ROSPATENT) 30.11.2011

6. Shrivel I. S., Maltsev I. M., Prokhorov V. T., korablina S. Y., ASP, T. M, Kushnareva I. A. (2015) On a new method for assessing the competence of experts for work in the customs examination // "Science and technology in the modern world: traditions and innovations" proceedings of II All-Russian scientific- practical conference with international participation, 19-20 November 2015: Novosibirsk, 2015. - p. 123-132.

7. Reva D. V., Maltsev I. M., Volkova G. Yu., Prokhorov V. T., S. Yu. Polukhina, Osina T. M. (2015) About the possibilities of new assessment tools to assess the quality of training of highly qualified specialists // the Collection "the role of the modern University technical personnel and modernization of the Russian economy collected works of the IX International scientific.-method. Conf.. Kostroma state technological University" / Kostroma, 2015. -p. 226-231.

8. Reva D. V., Shrivel I. S., Prokhorov V. T., Duyun, L. V., Maltsev, I. M., ASP, T. M. (2015) New possibilities of expert estimations as an instrument of evaluation of quality of preparation of experts // the Collection "the role of the modern University technical personnel and modernization of the Russian economy collected works of the IX International scientific.-method. Conf.. Kostroma state technological University" / Kostroma, 2015. -p. 22-28.

9. (2014) The quality revolution: through the ad or through a quality real: monograph V. T. Prokhorov [et al.]; under the General editorship of doctor of technical Sciences, Professor V. T. Prokhorov; VoIP (branch) of DSTU. Novocherkassk: URGU (NPI), 2014. - 384 p.

10. Prokhorov V. T., Osina T. M., Reva D. V., Duyun L. V., Zverev S. M. (2015) influence Of product concepts on the performance of footwear enterprises in the regions of SFD and NCFD (message 1) // Scientific almanac. 2015. No. 7 (9). -p. 740-753. 201

11. Prokhorov V. T., Osina T. M., Reva D. V., Duyun L. V., Zverev S. M. (2015) influence Of product concepts on the performance of footwear enterprises in the regions of SFD and NCFD (message 2) // Scientific almanac. 2015. No. 7 (9). -p. 754-767.

12. Reva D. V., Prokhorov V. T., Mishin Y. D., Korablina S. Y., Osina T. M., Tikhonov N. In. (2016) What action needs to be the most 


\begin{tabular}{l|lr|ll|ll} 
& ISRA (India) & $=\mathbf{1 . 3 4 4}$ & SIS (USA) & $=\mathbf{0 . 9 1 2}$ & ICV (Poland) & $=\mathbf{6 . 6 3 0}$ \\
Impact Factor: & ISI (Dubai, UAE) $=\mathbf{0 . 8 2 9}$ & PUH (Russia) $=\mathbf{0 . 2 0 7}$ & PIF (India) & $=\mathbf{1 . 9 4 0}$ \\
& GIF (Australia) & $=\mathbf{0 . 5 6 4}$ & ESJI (KZ) & $=4.102$ & IBI (India) & $=\mathbf{4 . 2 6 0}$ \\
& JIF & $=\mathbf{1 . 5 0 0}$ & SJIF (Morocco) & $=\mathbf{2 . 0 3 1}$ & & \\
\hline
\end{tabular}

effective to their implementation provoked to restore credibility to the domestic light industry// "New technologies and materials of light industry" - XII international scientificpractical conference with elements of scientific school for students and young scientists: Collection of articles. - Kazan, KAZAN technological University, 2016 - p. 45-52.
13. (2017) The concept of import substitution of products of light industry: background, challenges, and innovations : monograph / V. Prokhorov, T.[and others]; under the General editorship of Dr. sci. Sciences, Professor V. T. Prokhorov; the Institute of service sector and entrepreneurship (branch) don state technical University.- Mine: Isop (branch) DGTU, 2017. $-334 \mathrm{p}$. 